\title{
Tráfico de seres humanos e trabalho forçado: uma abordagem crítica ao fluxo de informações utilizado pela Organização Internacional do Trabalho
}

\author{
Priscila Martins Reis \\ Universidade Federal de Minas Gerais \\ Pedro Alves Barbosa Neto \\ Universidade Federal de Minas Gerais
}

\begin{abstract}
O tráfico de seres humanos, embora tenha origem remota, subsiste em escala global, notadamente em razão de elementos estruturais como a mobilidade forçada que o sistema capitalista impõe à força de trabalho. Todavia, o enfrentamento ao problema esbarra antes de tudo num impasse de ordem conceitual em razão da pluralidade de definições adotadas pelos países e organizações e da diversidade de abordagens e metodologias utilizadas. Esse contexto influencia o fluxo de informações sobre o tráfico de pessoas, questão aqui abordada por meio de pesquisa comparada. A amostra é composta por 10 países e os recursos documentais são os relatórios oficiais referentes à implementação das Convenções 29 e 105 sobre trabalho forçado encaminhados à Organização Internacional do Trabalho, examinados em sua natureza, explicitando-se suas semelhanças e diferenças.
\end{abstract}

Palavras-chave: tráfico de pessoas; trabalho forçado; fluxo de informações; organização internacional do trabalho.

La trata de personas y el trabajo forzoso: una aproximación crítica al flujo de informaciones utilizado por la Organización Internacional del Trabajo

La trata de seres humanos, aunque tenga origen remoto, existe en una escala mundial, principalmente debido a los elementos estructurales, tales como la movilidad forzada del sistema capitalista impone a la fuerza de trabajo. Sin embargo, la lucha contra la trata se ve obstaculizada por un problema de orden conceptual, por la diversidad de las definiciones adoptadas por los países y las organizaciones y la diversidad de enfoques y metodologías. Este contexto influye en el flujo de información sobre tráfico de seres humanos, una cuestión que se aborda aquí a través de la investigación comparativa. La muestra se compone de diez países y los recursos documentales son los informes oficiales relativos a la

Artigo recebido em 26 maio 2012 e aceito em 16 abr. 2013.

Rev. Adm. Pública - Rio de Janeiro 47(4):975-98, jul./ago. 2013 
aplicación de los Convenios 29 y 105 sobre el trabajo forzoso informes presentados a la Organización Internacional del Trabajo, examinó en su naturaleza, explicando las similitudes y diferencias.

Palabras clave: trata de personas; trabajo forzoso; flujo de información; Organización Internacional del Trabajo.

Human trafficking and forced labor: a critical approach to the information flow used by the International Labour Organization

Trafficking in persons, although it is a problem of remote origin, exists on a global scale, mainly due to structural elements such as the forced mobility that capitalist system imposes on the workforce. However, the fight against human trafficking faces an impasse of conceptual order because of the diversity of definitions adopted by the countries and organizations and the diversity of approaches and methodologies. This context influences flow of information on human trafficking, an issue addressed here through comparative research. The sample consists of ten countries and documentary resources are the official reports concerning the implementation of Conventions 29 and 105 on forced labor submitted to International Labour Organization, examined in its nature, explaining the similarities and differences.

KEYWORDs: trafficking in persons; forced labour; information flow, international labour organization.

\section{Introdução}

O tráfico de seres humanos ainda é um problema pungente em todo o mundo (Gueraldi e Dias, 2012:101). Como não poderia deixar de ser, o tráfico hoje apresenta peculiaridades que o distinguem de suas manifestações originárias já na Antiguidade, na medida em que as redes de exploração se tornaram mais refinadas e capilarizadas. A lógica mercadológica inerente ao sistema capitalista somada ao impulso dado pela globalização - por meio da redefinição das noções de tempo e espaço - asseguraram a existência de um ambiente fecundo para a ampliação do poder do capital sobre o trabalho e, assim, para proliferação das mais variadas formas de exploração laboral, dentre as quais se destaca o tráfico humano.

O tráfico está estreitamente vinculado aos fluxos migratórios, uma vez que sua configuração está relacionada a uma movimentação geográfica das vítimas. O fato é que grande parte dos casos de tráfico em que há exploração laboral dos aliciados se deve a uma busca por postos de trabalho. Do mesmo modo, dados evidenciam que parcela majoritária dos fluxos migratórios está atrelada a motivações de ordem profissional (ILO, 2010). Por essas razões, torna-se forçoso concluir que os fluxos migratórios se justificam muito mais por uma mobilidade forçada exigida pelo capital (Gaudemar, 1997) do que pela opção livre dos migrantes.

A falta de oportunidades e a dificuldade de acesso a bens e serviços básicos são responsáveis pela caracterização de efetiva circunstância de vulnerabilidade social, ampliando a probabilidade da ocorrência do tráfico de pessoas. Por outro lado, é inegável a existência de um mercado que consome ou demanda serviços em que comumente são alocadas vítimas tra- 
ficadas: mercado sexual, trabalho doméstico, fabril, entre outros (Sanguera, 2012:8; Weeks e Weeks, 2010:7; Gueraldi e Dias, 2012:179). Desse modo, é inegável que os fluxos migratórios e a lógica capitalista de mercado são componentes de suma relevância, que devem ser examinados para que seja empreendida uma abordagem adequada ao tráfico. Este deve ser o ponto de partida.

Contudo, o estudo da temática é árido, uma vez que a produção de conhecimento sobre tráfico de seres humanos ainda é muito deficiente. Esse problema não decorre tão somente do fato de a preocupação com o fenômeno ser relativamente recente e os estudos ainda serem escassos, mas principalmente da falta de precisão das informações produzidas e reproduzidas sobre o tráfico.

Há grande confusão acerca do entendimento do tráfico de pessoas em decorrência essencialmente da questão da definição. Os diversos Estados e organizações adotam conceitos diferenciados sobre o tráfico, o que implica, logicamente, confecção de dados diferenciados.

No entanto, o problema não se restringe à pluralidade de definições, mas também abarca o impasse trazido pela "abertura" dos significados, que possibilita a existência de uma diversidade de interpretações. Esse é o caso do Protocolo Adicional à Convenção das Nações Unidas contra o Crime Organizado Transnacional relativo à Prevenção, Repressão e Punição do Tráfico de Pessoas, em especial de Mulheres e Crianças — Protocolo de Palermo —, que cuida de definir o tráfico de seres humanos. Sua definição conta com ampla adesão, sendo, inclusive, aceita pela Organização Internacional do Trabalho (OIT). Ademais, mesmo os países que adotam o Protocolo não se encontram plenamente vinculados a seu texto, podendo promover adequações que entendam necessárias.

Destaca-se que as primeiras análises do tráfico de pessoas realizadas pela OIT se deram de modo incidental, vinculadas à abordagem do trabalho forçado, perspectiva que contribuiu para uma confusão no entendimento destes dois fenômenos - que são distintos - e, portanto, para a dificuldade de sua correta e harmônica concepção.

O que se pretende no presente artigo é examinar criticamente o conhecimento ora produzido a respeito do tráfico de pessoas e, assim, o fluxo de informações desenvolvido no escopo do controle da OIT em face da implementação das Convenções que tratam do trabalho forçado, notadamente no que tange ao enfrentamento do tráfico humano. Desse modo, pretende-se verificar se a abordagem vigente representa com fidelidade a problemática do tráfico e se subsidia a produção de dados quantitativos e qualitativos legítimos, considerando toda a complexidade que o tema envolve, dada a sua inserção na lógica capitalista de oferta e demanda.

A análise proposta justifica-se pelo fato de fazer-se necessária uma abordagem diversa da comumente realizada, trabalhando de forma crítica as informações empregadas, tendo em vista seu método de produção e os interesses que influenciaram esse processo.

Para concretizar o objetivo proposto, elegeu-se uma pesquisa exploratória, levantandose a bibliografia sobre o tema e os documentos oficiais que subsidiaram a análise empírica da proposta. Como referencial teórico, foi adotado o conceito de tráfico humano trazido pelo Protocolo de Palermo, ratificado pelo Brasil em 2004. 
No que tange à organização do presente estudo, propôs-se, em um primeiro momento, um exame das origens estruturais do problema, seguido por uma abordagem crítica das definições atribuídas ao fenômeno, que culmina no reconhecimento da predominância do conceito trazido pelo Protocolo de Palermo, evidenciando sempre suas imprecisões, que acabam por gerar obstáculos para a produção de conhecimento sobre o tráfico de pessoas. A seguir, analisou-se especificamente a dimensão informacional, avaliando-se em que medida a abordagem da OIT proporciona de modo eficaz a coleta sistematizada de informação fiável acerca do tráfico humano.

\section{Mobilidade do trabalho, migrações e tráfico de seres humanos}

O tráfico de seres humanos está estreitamente vinculado aos fluxos migratórios, uma vez que sua configuração está relacionada a uma movimentação geográfica das vítimas seja dentro de ou entre fronteiras nacionais. O fato é que grande parte dos casos de tráfico em que há exploração laboral dos aliciados se deve a uma busca por postos de trabalho e, assim, a verdadeiras estratégias de sobrevivência.

A falta de mecanismos de inclusão trabalhista dos indivíduos em suas comunidades ou países de origem estimula a procura por novos espaços em que possam obter colocações profissionais (Stalker, 1994:23). Essas pessoas econômica e profissionalmente marginalizadas se tornam vítimas potenciais de aliciadores e empregadores que desejam reduzir os custos com a contratação, porquanto, em regra, oferecem menor resistência a condições abusivas de trabalho seja em razão da necessidade premente em que se encontram, do preconceito que não raro enfrentam (Stalker, 1994:61) ou, muitas vezes, em virtude da irregularidade de seu status migratório. O quadro se agrava na medida em que há hoje um exército de reserva industrial que não se restringe aos ditos "Países de Terceiro Mundo", alcançando dimensões mundiais (Mészáros, 2003), fato este que estimula não só a migração como também a exploração do trabalhador em escalas globais.

O que fica claro é que a maior parte das pessoas que migram é movida preponderantemente por necessidade e não por vontade pessoal (Weeks e Weeks, 2010:18). Aliás, dados demonstram que os fluxos de pessoas são predominantemente justificados por razões laborais, ou seja, por objetivos de colocação no mercado de trabalho. Segundo a OIT, em 2010, o número de trabalhadores migrantes chegou a 105 milhões de pessoas, o que representa $90 \%$ do número de migrantes internacionais (ILO, 2010).

Essa constatação nos faz inevitavelmente refletir sobre a mobilidade que o trabalho assume na economia capitalista. O trabalho, nos moldes da organização capitalista, atua como fator de produção e, assim, como um dos alicerces que sustentam a acumulação do capital. Para bem desempenhar esse papel, como já delineava Karl Marx (1993) em seu materialismo histórico dialético, necessário é que seja flexível, ou melhor, tenha mobilidade para que se coloque livremente disponível para a apropriação do capital, assumindo traços de mercadoria e, assim, contando com valor de uso e de troca. 
Vale dizer que, para que seja pensado como mercadoria, que se coloca à disposição do mercado, o trabalho deve estar atrelado à noção de liberdade, ao menos quanto à possibilidade de ir e vir. No entanto, deve-se destacar que a liberdade desses indivíduos não é plena no que tange à venda da força de trabalho, eis que não possuem condições efetivas de escolherem os postos de trabalho, guiando-se, a bem da verdade, de acordo com as oportunidades oferecidas pelo capital. Nesses termos é que se revela impróprio pensar a migração dos trabalhadores como consequência de decisões estritamente pessoais, porquanto os movimentos são condicionados aos interesses do capital, conforme sustenta Jean-Paul de Gaudemar (1997:17).

Ainda de acordo com Gaudemar (1997:21), a mobilidade do trabalho não se restringe aos deslocamentos geográficos — que é uma de suas várias facetas —, mas também diz respeito a alterações dos espaços ocupados pelo trabalhador no processo produtivo e quaisquer outras modificações ou adaptações exigidas pelo modelo mercadológico capitalista competitivo, como a necessidade de incessante qualificação profissional. Em todos os casos, vale dizer, a mobilidade é forçada e caracterizadora do domínio que o capital exerce sobre a força de trabalho.

A mobilidade do trabalho, desse modo, deve ser considerada um dos principais fatores que contribuem para a intensificação dos fluxos migratórios e também para a proliferação de variadas formas de exploração da mão de obra, dentre elas, as perpetradas por meio do tráfico humano. A propósito, partindo mais uma vez da obra de Marx (1993), pode-se trazer à tona a noção de mais-valia para caracterizar a exploração laboral via tráfico humano como tentativa máxima de redução dos custos inerentes à reprodução do trabalhador.

A mais-valia proposta por Marx é resultado da diferença entre o valor produzido pelo indivíduo por meio de seu trabalho e o valor que lhe é atribuído como salário, diferença essa apropriada pelo beneficiário do labor desempenhado. Como as vítimas traficadas comumente nada ou pouco recebem pelo labor realizado, a mais-valia alcança com esta prática criminosa alargadas dimensões. A propósito, A OIT já abordou essa questão com o intuito de estimar o custo da coerção, concluindo que, consideradas as diferenças salariais não pagas e os valores cobrados das vítimas a título de despesas com o recrutamento, os traficantes auferem anualmente, em média, R\$ 21 bilhões de dólares (OIT, 2009:34).

Ainda na abordagem dos elementos responsáveis pela origem do tráfico, merece destaque o fato de que a prática assume movimento circular. Os resultados das ações do poder público nas fiscalizações e na regularização de situações de trabalho degradante decorrentes do tráfico demonstram que muitas das vítimas reincidem no contexto de exploração. Na verdade, o indivíduo se reinsere em tais mecanismos de espoliação por falta de oportunidades, por ausência de condição efetiva de escolha livre.

Ao tratar dos elementos causadores ou ampliadores da vulnerabilidade ao tráfico, necessário considerar que, lamentavelmente, "problemas estruturais globais que produzem o tráfico - globalização, patriarcado, racismo, conflitos e guerras étnicas, devastação ecológica e ambiental e perseguição política e religiosa - são raramente tocados no paradigma hegemônico sobre o tráfico" (Kempadoo, 2005:78), muito embora sejam cruciais para a "decisão" migratória - que marca justamente o início do tráfico humano. Além disso, a preservação 
de um contexto social instável e precário propicia a reprodução do tráfico, na medida em que o alimenta incessantemente com potenciais vítimas, isto é, com indivíduos sem alternativas reais de subsistência e realização pessoal e, via de consequência, mais propensos à aceitação de oportunidades em outros espaços (OIT, 2001:40; OIT, 2005:61).

Tendo em vista esses elementos, revela-se imprescindível uma reflexão acerca das causas do tráfico, de modo a considerar os fatores que colocam os indivíduos em condição de vulnerabilidade social (IBGE, 2007:31). Ressalte-se que o termo vulnerabilidade é empregado na qualidade de ferramenta hábil para abranger uma multiplicidade de formas de exposição da pessoa humana a condições inaceitáveis no mercado de trabalho, rejeitando-se uma visão bipolarizada dos sujeitos, agrupando-os de modo simplista em incluídos ou excluídos. Nessa linha, não há que se considerar em condição de vulnerabilidade social apenas os trabalhadores que não estão amparados pela formalidade, mas também todos os obreiros que, mesmo ocupando postos formais de trabalho, não se encontram em condições de labor condizentes com uma noção de trabalho decente.

Considerando que a OIT atrela à noção de trabalho decente a garantia de labor socialmente protegido, produtivo e de qualidade, ${ }^{1}$ há de se reconhecer que o mercado de trabalho atual oferece diversificados exemplos de trabalho incompatíveis com esse parâmetro. Como decorrência, o quadro de potenciais vítimas do tráfico assume feições grandiosas, uma vez que esses deficits de trabalho decente "seja em uma determinada região, seja em um determinado setor da economia" apresentam "capacidade latente de expulsar trabalhadores e trabalhadoras em busca de melhores condições de vida" (Sprandel, Penna e OIT, 2009:20). Por essa razão é que é de suma importância atuar sobre essa circunstância, corrigindo-a, como modo indireto de enfrentamento ao tráfico humano.

\section{A abordagem da Organização Internacional do Trabalho quanto ao tráfico de seres humanos e suas implicações}

A Convenção no 29 da OIT, de 1930, versa sobre o trabalho forçado ou obrigatório, definindo-o como "todo trabalho ou serviço exigido de uma pessoa sob ameaça de sanção e para o qual ela não tiver se oferecido espontaneamente”. A amplitude dessa significação já apontava, desde aquele momento, a complexidade do tema, que abarca uma grande diversidade de condutas. Não obstante fosse de certo modo positiva a generalidade do conceito por permitir a inclusão em seu bojo dos mais variados tipos de comportamento, ela também acabava por trazer dificuldades no que tange à sua identificação nos casos concretos.

A Convenção no 105 , de 1957, também da OIT, trata da abolição do trabalho forçado. A motivação para a edição de uma nova convenção sobre o tema residiu justamente no

\footnotetext{
${ }^{1}$ ORGANIZAÇÃO INTERNACIONAL DO TRABALHO. O que é trabalho decente. Disponível em: <www.oit.org.br/content/o-que-e-trabalho-decente>. Acesso em: 5 mar. 2012.
} 
contexto pós-Segunda Guerra Mundial, no qual se multiplicou o recurso ao trabalho forçado por motivos de ordem política e ideológica. Essa convenção, nessa linha, veda o recurso ao trabalho forçado para fins de desenvolvimento econômico, educação política, discriminação, disciplinamento ou punição diante da participação em greves.

Em sede de sua Declaração sobre os Princípios e Direitos Fundamentais no Trabalho, do ano de 1998, a OIT ressaltou que a livre incorporação dos Estados implica aceitação dos princípios e direitos enunciados em sua fundação e, assim, comprometimento quanto ao empreendimento dos esforços necessários para concretizá-los. A mesma declaração sustenta ainda que a condição de membros da OIT compele os países à obediência de tais princípios e direitos, expressos em convenções, mesmo que não as tenham ratificado. ${ }^{2}$ Nesse sentido, como a "eliminação de todas as formas de trabalho forçado ou obrigatório" representa um dos quatro princípios concernentes aos direitos fundamentais no trabalho, é pressuposto o seu reconhecimento por todos os países-membros da OIT (Novais, 2008:115).

A OIT entende que a noção de trabalho forçado está essencialmente ligada à de ausência de liberdade, distinguindo-a do trabalho degradante. Assim, para que se configure o trabalho forçado, necessário que haja privação de liberdade pelos mais diversos meios, o que inclui a apreensão de documentos, o encaminhamento dos trabalhadores a locais geograficamente isolados e a manutenção de guarda armada para evitar fugas. Desse modo, a Organização concebe que toda forma de trabalho forçado é degradante, contudo a recíproca nem sempre é verdadeira (OIT, 2011:26).

Tema que tem ganhado espaço nas discussões acerca da exploração da mão de obra, submetendo inúmeros trabalhadores a trabalho forçado e degradante, é o tráfico de seres humanos. Trata-se de um grave impasse que assola a população mundial como um todo, eis que envolve não só os países mais pobres, como também as nações mais abastadas. Isso porque, se aqueles são as grandes fontes de recrutamento de vítimas, essas representam o local de destino, onde ocorre a exploração dos aliciados. Não se deve olvidar, ainda, a situação crítica ocupada pelos países que representam rotas para o fluxo dessas pessoas.

Ainda que o tráfico de seres humanos seja responsável pela submissão, todo ano, de inúmeras pessoas a condições extremamente degradantes de trabalho, e, portanto, evidentemente incompatíveis com a noção de trabalho decente sustentada pela OIT, a Organização ainda não se debruça normativamente sobre o tema. Na verdade, o problema do tráfico de pessoas inicialmente fora ponderado quando da análise da implementação das convenções sobre trabalho forçado e, muito embora haja estudos mais recentes sobre o tema, o tratamento normativo ainda é inexistente.

A OIT adota a definição de tráfico de pessoas trazida pelo Protocolo de Palermo, que aduz configurar tráfico de seres humanos as seguintes condutas:

\footnotetext{
${ }^{2}$ São os princípios relativos aos direitos fundamentais: “a) a liberdade sindical e o reconhecimento efetivo do direito de negociação coletiva; b) a eliminação de todas as formas de trabalho forçado ou obrigatório; c) a abolição efetiva do trabalho infantil; e d) a eliminação da discriminação em matéria de emprego e ocupação" (OIT, 1998).
} 
(...) o recrutamento, o transporte, a transferência, o alojamento ou o acolhimento de pessoas, recorrendo à ameaça ou uso da força ou a outras formas de coação, ao rapto, à fraude, ao engano, ao abuso de autoridade ou à situação de vulnerabilidade ou à entrega ou aceitação de pagamentos ou benefícios para obter o consentimento de uma pessoa que tenha autoridade sobre outra para fins de exploração. A exploração incluirá, no mínimo, a exploração da prostituição de outrem ou outras formas de exploração sexual, o trabalho ou serviços forçados, escravatura ou práticas similares à escravatura, a servidão ou a remoção de órgãos (United Nations, 2000).

A Organização, em suas publicações sobre as Convenções n. 29 e n. 105, aborda o tráfico de seres humanos como uma das possíveis manifestações do trabalho forçado (OIT, 2001:14-15), muito embora conclua que majoritariamente (80\% dos casos) o trabalho forçado não está ligado ao tráfico (OIT, 2005:15-16). ${ }^{3}$ Esse enfoque acarreta alguns problemas no que diz respeito à correta apreensão do seu significado. A própria OIT reconhece a escassez de informações confiáveis sobre o tráfico de seres humanos, aduzindo que "são muito limitados os dados oficiais ou pesquisas analíticas" (OIT, 2005:51).

Um leitor incauto poderia acabar por entender que o tráfico de pessoas corresponde tão somente a uma espécie do gênero de trabalho forçado, sem considerar todas as suas outras manifestações que podem, inclusive, não tangenciar o trabalho. O primeiro ponto que deve ficar claro é que o tráfico de seres humanos corresponde a fenômeno de grande amplitude, ${ }^{4}$ que também, em algumas de suas manifestações, afeta sobremaneira a mão de obra e que, por isso, merece tratamento específico da OIT.

Mas não é só. Conforme o texto do Protocolo de Palermo e, ainda, a própria manifestação da OIT, insere-se dentro da definição de tráfico de pessoas proposta pela ONU a noção de trabalho forçado como uma das possíveis finalidades da captação das vítimas do tráfico humano. Nesse ponto, a relação gênero-espécie parece se inverter.

Na verdade, a redução das temáticas a uma simples relação de gênero e espécie será de todo modo inadequada, devendo-se ter em mente que o trabalho forçado e o tráfico de pessoas correspondem a fenômenos que podem se dar de modo entrelaçado, mas essa não é uma condição necessária. O que se constata, de forma ampla, é que as definições de tráfico de seres humanos adotadas pelos diversos Estados e pelas entidades em geral não são homogêneas, o que contribui sobremaneira para a inexatidão das informações sobre a problemática que ora se repetem. Um estudo cauteloso das informações divulgadas deve levar em conta não só a definição adotada, mas também a metodologia utilizada e as orientações políticas e

\footnotetext{
3. Contudo, é de se destacar que a interligação das temáticas não é de pouca relevância, porquanto no Relatório de 2009 o trabalho forçado realizado via tráfico de pessoas está inserido nas três principais formas de trabalho forçado atuais (OIT, 2009:11).

${ }^{4}$ Se em sua origem o tráfico humano se restringia à exploração da mão de obra escrava, nos dias atuais, a prática é um tanto mais complexa, abrangendo diversas modalidades de ofensa aos direitos humanos tais como a exploração sexual, a pornografia infantil, a adoção irregular, o comércio de órgãos, a exploração do trabalho humano em condições análogas à escravidão, o contrabando de mercadorias, bem como o tráfico de armamento e de entorpecentes.
} 
ideológicas pressupostas (Grupo Davida, 2005:155-182; Piscitelli, 2008:43; Andrees e N. J. van der Linden, 2005:60).

É de se destacar que o impasse da falta de precisão afeta, inclusive, o conhecimento no que tange à quantificação do número de vítimas. De um lado, o Relatório Global do Escritório das Nações Unidas sobre Drogas e Crimes (UNODC) de 2009 indica que 4 milhões de pessoas são vítimas do tráfico de seres humanos por ano. De outro, a Organização Internacional do Trabalho (2005:15) estima que aproximadamente 2,5 milhões de indivíduos são submetidos anualmente ao tráfico para fins comerciais ou para exploração sexual.

Essa questão também tem origem no problema da definição, pois diferentes acepções do tráfico humano, fundadas em leques de condutas distintas, obviamente culminam em quantitativos diferenciados. Na verdade, "como o tráfico é uma atividade clandestina, definida de forma vaga e conflitante pelos vários Estados e entidades que o combatem, os dados quantitativos não são confiáveis" (Grupo Davida, 2005:155).

Ainda que o posicionamento predominante seja no sentido de adotar a definição do Protocolo de Palermo, o problema da imprecisão persiste. O Protocolo não cuida de definir certas expressões cruciais como "outras formas de coerção", "abuso de poder ou de uma situação de vulnerabilidade" e "outras formas de exploração sexual", deixando ampla margem interpretativa para os Estados. Além disso, os países que adotam o Protocolo não estão obrigados a recepcionar a integralidade de seu texto, podendo fazer adequações, reduções ou ampliações que entendam necessárias.

Vale registrar ainda que o Protocolo de Palermo tem como foco a criminalidade internacional organizada, razão pela qual sua abordagem é de cunho repressivo. Essa perspectiva não parece ser a mais adequada quando o objetivo reside na tutela de direitos essenciais ao indivíduo, notadamente da sua dignidade, que também se manifesta no trabalho (Sprandel, Penna e OIT, 2009:19).

Ocorre que a abordagem repressiva, em si, tem sido adotada de modo inadequado, pois sob uma roupagem de combate ao tráfico de pessoas combate-se, na verdade, a violação de leis nacionais de imigração e de trabalho sexual (Sanguera, 2012:10-13). Esse é um alerta necessário já feito pela OIT: “Onde há legislação específica sobre tráfico, esta muitas vezes se concentra na prostituição. Outro tipo de legislação contempla, de maneira mais geral, penalidades para contrabando ou exploração de imigrantes" (OIT, 2001:76).

Esses tipos de abordagens cuidam de ampliar o estigma que paira sobre as vítimas. De um lado, o repúdio à prostituição (Kempadoo, Sanguera e Pattanaik, 2012:xi-xiii), empreendido de modo oculto, com fulcro em preconcepções e conservadorismos, sob o manto da erradicação do tráfico de pessoas, contribui sobremaneira para o incremento da violência sofrida pelas pessoas traficadas, que são fortemente estigmatizadas. O tráfico humano, conforme já explanado, não se restringe à exploração sexual, sendo inadequada tal associação. Ademais, nem toda prática da prostituição está entrelaçada ao tráfico (Kempadoo, 2005:64).

Por outro lado, se o foco é a criminalidade organizada internacional, a presença do imigrante acaba por ser vista como uma possível ameaça ou indício de ilegalidade. O repúdio ao tráfico passou, assim, a estar atrelado às medidas de controle da imigração, que vêm sendo 
recrudescidas como reação, inclusive, contra ataques terroristas principalmente após o incidente de 11 de setembro de 2001 (Kapur, 2012:34-36). A OIT, porém, alerta que essa não é uma política prudente, pois "o tráfico de mão de obra teoricamente não teria lugar se a pessoa que busca emprego tivesse a liberdade de movimentação geográfica e liberdade de acesso ao emprego" (OIT, 2001:73), além do fato de que "o acesso restrito a canais legais de migração tem contribuído para o crescimento do negócio de recrutamento privado, que, muitas vezes, opera nas fronteiras do tráfico de pessoas" (OIT, 2005:53).

Via de consequência, uma vez verificada a ocorrência do tráfico de pessoas, as medidas geralmente adotadas não são tutelares no que tange às vítimas. Os imigrantes, em regra, são presos e deportados.

\section{0 monitoramento da aplicação das normas internacionais do trabalho}

As recorrentes mudanças na economia e no cenário internacional a partir das décadas finais do século XX e do início do século XXI impactaram diretamente os padrões de migração entre as nações e mesmo dentro de seus territórios. Nos últimos anos uma nova tendência vem sendo observada, afinal, o número de migrantes com destino aos países desenvolvidos vem caindo significativamente. Essa situação contribui para o enfraquecimento do estereótipo vigente de um fluxo migratório unilateral em que pessoas dos países subdesenvolvidos se deslocariam em direção aos países de economia desenvolvida.

Todavia, apesar do declínio dos fluxos de migração clássicos, o volume migratório continua a subir. O World Migration Report do ano de 2011, publicado pela International Organization for Migration, informa que, em 2010, o número total de migrantes internacionais em todo o mundo foi estimado em 214 milhões de pessoas, o que significa um aumento significativo quando comparado aos 191 milhões de pessoas contabilizadas em 2005. ${ }^{5}$

Considerando as estatísticas supramencionadas e que o número estimado de migrantes internos é de 740 milhões de pessoas (UN, 2010), tem-se que atualmente o número de migrantes se aproxima de 1 bilhão de pessoas, o correspondente a um sétimo da população do planeta.

A partir desse cenário emerge um novo olhar sobre os fluxos migratórios, que possibilita uma ampliação da compreensão do fenômeno. Deve-se ponderar se os países tradicionalmente emissores de migrantes, agora na condição de países de destino, estão legalmente preparados para oferecer a devida proteção aos imigrantes, uma vez que a deficiência na tutela de direitos propicia práticas abusivas como o tráfico humano.

Há que se considerar que os fluxos migratórios, quando analisados a partir de critérios regionais, podem apresentar contornos muito diversos. Como exemplo disso, observamos que, no contexto africano, os fluxos migratórios são essencialmente intrarregionais, de modo

${ }^{5}$ Os dados são do Departamento de Assuntos Econômicos e Sociais da Organização das Nações Unidas. 
que, de acordo com o Banco Mundial, até o ano de 2011, apenas 3\% da população africana havia migrado para fora do continente.

O contexto americano atual reflete, de maneira direta, os impactos da crise de 2008 e suas consequências econômicas. Os países desenvolvidos desse continente - Estados Unidos e Canadá - vêm endurecendo suas políticas de imigração, sobretudo, no que tange os países sul-americanos. Observa-se, além disso, um intenso fluxo migratório intrarregional entre os países latino-americanos graças aos avanços econômicos alcançados por alguns Estados, destacadamente: Brasil, Chile e Argentina. Nesse novo contexto, esses países passaram a ser considerados destinos atraentes para emigrantes dos países vizinhos que apresentam situação econômica ainda insuficiente.

Quando analisada a realidade asiática, observam-se diversas variáveis que contribuem para o desenho dos fluxos migratórios. Dentre elas destacam-se as intempéries naturais muito frequentes naquele continente e que geram, em não raros casos, a necessidade de deslocamento de pessoas de áreas devastadas para áreas consideradas mais seguras dentro ou fora das fronteiras nacionais. Além disso, pode ser percebida uma forte tendência de migração intrarregional neste continente. Segundo dados de 2011 do Banco Mundial, cinco dos 10 principais países de emigração são asiáticos - Bangladesh, China, Índia, Paquistão e Filipinas - e países como Cingapura, Malásia, Tailândia, Hong Kong e Coreia do Sul se destacam por serem os principais destinos dos migrantes asiáticos. Aliados a esses fatores, os altos índices populacionais e as crescentes taxas de desemprego somam-se às causas principais para o intenso fluxo migratório encontrado no continente asiático.

A situação europeia se mostra em constante transformação desde a deflagração da crise de 2008-09. O crescente desemprego em praticamente todos os países da Europa Ocidental gerou uma onda de migração intensa nos últimos anos. Além disso, de acordo com a Organização Internacional de Migrações, é possível perceber fortes consequências sociais que recaíram sobre os imigrantes nos países europeus, sobretudo no que diz respeito aos movimentos xenofóbicos e a uma maior propensão por parte dos imigrantes em relação ao desemprego.

A Oceania apresenta um alto índice migratório, principalmente quando analisados especificamente os contextos dos dois principais países de destino. O Departamento de Assuntos Econômicos e Sociais da ONU dá conta de que existem na Oceania 35 milhões de pessoas. Esse número, quando aplicado nas proporções nacionais de Austrália e Nova Zelândia, revela que $21,9 \%$ e $22,4 \%$ do total da população, respectivamente, são imigrantes. A exemplo dos casos de Estados Unidos e Canadá, Austrália e Nova Zelândia passaram desde 2010 a aplicar políticas públicas mais rígidas quanto à entrada de novos imigrantes.

As características díspares entre as regiões do planeta, quando analisada a questão dos fluxos migratórios, se aliam a outros fatores para obstaculizar o estabelecimento de um retrato fiel da situação dos migrantes em uma escala global. Afinal, o recolhimento de estatísticas e informações acerca da realidade das pessoas que se deslocam de seus lugares de origem se torna de extrema complexidade, já que, em muitos casos, a migração ocorre fora dos limites burocráticos previstos pelos Estados, não permitindo, assim, os registros dos mais básicos fatores determinantes da prática migratória. 
Exemplo indubitável dessa realidade é a migração forçada provocada pelo Tráfico de Seres Humanos. Conforme o Departamento de Estado Norte-americano — 2011 —, o número global de pessoas traficadas em 2010 se manteve em franco crescimento. Essas estatísticas incluem adultos e crianças que se encontram em situação de trabalho forçado, servidão por dívida e prostituição forçada. É estimado que, em todo o globo, duas a cada mil pessoas são vítimas de tráfico humano. Se analisadas regiões como a Ásia, esse índice pode aumentar para três a cada mil habitantes.

Essas deficiências informacionais comprometem a atuação de Órgãos Internacionais de controle da aplicação de normas internacionais que vedam essas práticas criminosas. Por essa razão, o exame das informações oficiais sobre o tráfico humano demanda cautela e olhar crítico.

Muito embora existam diversificadas fontes de informação sobre o cumprimento e a aplicação das normas internacionais do trabalho, de maneira geral, os comitês especializados da ONU e de suas agências especializadas — como a OIT —, que avaliam a aplicação das normas internacionais no âmbito das legislações e das práticas nacionais, executam a tarefa de identificar informações relevantes, verdadeiras e confiáveis levando em conta preponderantemente dados provenientes dos Estados-membros das organizações internacionais. Desse modo, questões relacionadas a natureza, forma e conteúdo destas informações vinculam-se diretamente ao interesse de cada Estado-membro em cooperar com o sistema de controle. ${ }^{6}$

Ressalta-se que, com a crescente especialização técnica da OIT e o consequente aumento do número de convenções e recomendações adotadas, a Declaração de 1998 estabeleceu uma mudança nos prazos de envio dos relatórios. A partir de então os relatórios contendo informações sobre as oito convenções fundamentais e sobre as quatro convenções consideradas prioritárias passaram a ser solicitados a cada dois anos (Barzotto, 2007).

O comitê de peritos tem se esforçado para estabelecer um padrão a ser seguido pelos países na preparação dos relatórios. Geralmente as informações são solicitadas de acordo com os artigos constantes nas convenções ou recomendações. Isso significa que, a cada artigo, individualmente, o comitê solicitará informações sobre sua aplicação na legislação e na prática.

Ocorre que, muitas vezes, os dados levantados são coletados por métodos de amostragem. Este tipo de pesquisa, segundo Hilton (2003), não contempla alguns critérios como a abrangência de área geográfica e, portanto, não revelam a real situação de determinado Estado. Outra questão importante sobre as informações que compõem estes relatórios é sua vulnerabilidade em relação aos atores engajados na coleta de dados e também na produção, sistematização e envio desta informação. As etapas de produção e de sistematização da informação são as que sem dúvida apresentam características de maior fragilidade. Essa fragilidade se dá na medida em que essas informações refletem o ponto de vista de pessoas

\footnotetext{
${ }^{6}$ A obrigação de enviar relatórios sobre o status da implementação das convenções e recomendações é originada pelo art. 22 da Constituição da OIT.
} 
que produzem os relatórios e dos organismos aos quais elas estão vinculadas, e desta forma podem apresentar vieses, não correspondendo, assim, a uma informação imparcial.

Nesse sentido, as organizações de empregados e empregadores mais representativas de cada Estado-membro são convocadas a integrar o grupo dos atores envolvidos nos processos informacionais da Organização Internacional do Trabalho. Solicita-se aos governos que enviem cópias dos relatórios a essas organizações, para que seus representantes possam tecer comentários sobre as informações inseridas originalmente pelo governo. A essa atividade dá-se o nome de controle social da informação, fenômeno que "contribui para desmistificar o discurso jurídico produzido pelas indústrias de informação e por governos, e que estimula o exercício da atividade cidadã de um modo mais prático e político, em oposição a um modelo puramente técnico e econômico, como atualmente é percebido" (Blotta e Mattos, 2008:28).

Em se tratando especificamente das convenções da OIT que regulam o trabalho forçado — Convenções no 29 e no 105 —, tem-se que ambas, conforme dito alhures, integram o rol das convenções fundamentais segundo a Declaração de 1998 da Organização. Em função disso, os relatórios sobre a implementação dessas convenções no âmbito dos Estados-parte devem ser submetidos à apreciação pelo Comitê de Peritos com periodicidade bianual.

A partir da análise de uma amostra de 10 países com indicadores socioeconômicos e sistemas administrativos muito diferentes, este trabalho oferece um panorama do processo informacional estabelecido para o monitoramento das Convenções que versam sobre a eliminação do trabalho forçado da OIT. A escolha dos países se deu com intuito de delimitar uma amostra global e, ao mesmo tempo, heterogênea do ponto de vista econômico, administrativo e jurídico. Optou-se por esse modelo de escolha com o objetivo de conferir aos resultados obtidos a maior amplitude e o maior grau de isenção possíveis.

Todos os relatórios oficiais enviados a partir do ano de 1990 foram analisados com o objetivo de entender as principais características das informações enviadas ao Comitê de Peritos. Os seguintes países compuseram a amostra:

v Continente africano: Angola e Egito;

v Continente americano: Brasil e Canadá;

v Continente europeu: França e Turquia;

v Continente asiático: Japão e Índia;

Oceania: Austrália e Indonésia.

Numa análise inicial verificou-se se há adequação do Estado diante da solicitação do envio periódico dos relatórios oficiais. Assinala-se que todos os países integrantes da amostra são signatários das Convenções no 29 e nํㅜ 105. Os quadros 1 e 2 oferecem um panorama do envio das informações. 


\begin{tabular}{|c|c|c|c|}
\hline País/Situação & Ano da Ratificação C. 29 & $\begin{array}{l}\text { Enviou informações } \\
\text { sobre a C. } 29\end{array}$ & $\begin{array}{l}\text { Adequação periodicidade } \\
\text { sobre a C. } 29\end{array}$ \\
\hline Angola & 1976 & Não & $x$ \\
\hline Egito & 1955 & Sim & Não \\
\hline Brasil & 1957 & $\operatorname{Sim}$ & $\operatorname{Sim}$ \\
\hline Canadá & 2011 & Não & $x$ \\
\hline França & 1937 & Sim & Não \\
\hline Turquia & 1998 & Sim & Sim \\
\hline Israel & 1955 & Não & $x$ \\
\hline Índia & 1954 & Sim & Sim \\
\hline Austrália & 1932 & $\operatorname{Sim}$ & $\operatorname{Sim}$ \\
\hline Indonésia & 1950 & Sim & Sim \\
\hline
\end{tabular}

Fonte: Quadro elaborado pelos autores com base nos relatórios governamentais. ${ }^{7}$

Em se tratando da obrigação de fornecer informações acerca da implementação da Convenção no 29 , observa-se uma tendência positiva em relação aos países analisados. Apenas três dos 10 países da amostra não enviaram nenhum relatório sobre a aplicação da Convenção $\mathrm{n}^{\circ}$ 29 em seus territórios: Angola, Canadá e Israel. Ademais, todos os outros países enviaram no mínimo dois relatórios oficiais cada um.

A respeito da periodicidade do envio dos relatórios ao comitê de peritos, percebe-se alto grau de negligência por parte de metade dos países analisados, dado que apenas Brasil, Turquia, Índia, Austrália e Indonésia cumpriram com o compromisso de enviar periodicamente informações sobre a aplicação da Convenção no 29.

Outro fato interessante é a lacuna temporal existente entre o ano em que se deu a ratificação da Convenção por país e o envio do primeiro relatório oficial sobre sua implementação nos âmbitos nacionais. Diversas podem ser as razões para a ocorrência desse fenômeno, como a existência de instabilidade política temporária, períodos de conflitos bélicos ou situações atípicas que demandem atenção especial do Estado, fazendo com que a tarefa informacional ocupe uma posição secundária no ranking de prioridades nacionais. Além disso, a entrada em vigor de um instrumento internacional muitas vezes não ocorre automaticamente após a ratificação pelo Estado. A vigência de uma convenção internacional está diretamente atrelada ao modelo jurídico-legislativo apresentado por país, que pode variar imensamente. Todavia,

${ }^{7}$ Os relatórios oficiais foram acessados no endereço: <www.ilo.org/ilolex/english/>. 
a análise das possíveis causas acerca do atraso do envio dos primeiros relatórios não se configura como objeto de investigação do presente trabalho.

\section{Quadro 2 \\ Envio das informações acerca da implementação da Convenção no 105 sobre a abolição do trabalho forçado de 1957}

\begin{tabular}{|cccc|}
\hline País/Situação & $\begin{array}{c}\text { Ano da Ratificação } \\
\text { C. } 105\end{array}$ & $\begin{array}{c}\text { Enviou informações } \\
\text { sobre a C. 105 }\end{array}$ & $\begin{array}{c}\text { Adequação periodicidade } \\
\text { sobre a C. 105 }\end{array}$ \\
Angola & 1976 & Sim & Não \\
Egito & 1958 & $\operatorname{Sim}$ & Não \\
Brasil & 1965 & $\operatorname{Sim}$ & Sim \\
Canadá & 1959 & $\operatorname{Sim}$ & Sim \\
França & 1969 & Sim & Não \\
Turquia & 1961 & Sim & Sim \\
Israel & 1958 & Não & $X$ \\
Índia & 2000 & Não & $X$ \\
Austrália & 1960 & Não & X \\
Indonésia & 1999 & Sim & Não \\
\hline
\end{tabular}

Fonte: Quadro elaborado pelo autor com base nos relatórios governamentais.

O quadro 2 apresenta uma situação menos satisfatória quanto à formalidade do fornecimento de informações a respeito da implementação da Convenção no ${ }^{0} 105$. Isto porque, se, por um lado, a quantidade de países que enviaram pelo menos um relatório oficial permanece a mesma, sete; por outro lado, a quantidade de países que atenderam à solicitação da OIT quanto à periodicidade bianual é menor, de modo que somente quatro países enviaram informações oficiais no prazo estabelecido de dois anos: Brasil, Canadá, França e Turquia.

Há que se mencionar a posição de destaque ocupada por Brasil e Turquia quanto à formalidade do envio de informações ao comitê de peritos, afinal, esses dois países figuram positivamente tanto no envio de informações como na periodicidade solicitada para o monitoramento de ambas as convenções.

Ressalta-se que as Convenções no 29 e no 105 regulam e vedam, de certo modo, a mesma categoria de prática social. Por ser assim, em alguns casos, como nos relatórios brasileiros de 1993, 1994 e 2005, tem-se que o país enviou apenas uma notificação, na qual advertia o comitê de peritos que toda a informação acerca da aplicação da Convenção no 105 em seu território já havia sido encaminhada no âmbito do relatório oficial sobre a implementação da Convenção no 29. 


\section{Quadro 3}

Tipologia das informações enviadas para monitoramento da implementação da Convenção no 29

\begin{tabular}{|c|c|c|c|c|c|c|c|}
\hline País & $\begin{array}{c}\text { Mudança } \\
\text { na } \\
\text { legislação }\end{array}$ & $\begin{array}{l}\text { Políticas } \\
\text { públicas/ } \\
\text { programas }\end{array}$ & $\begin{array}{c}\text { Resultados } \\
\text { de ações } \\
\text { públicas }\end{array}$ & $\begin{array}{l}\text { Situações } \\
\text { específicas }\end{array}$ & $\begin{array}{c}\text { Informações } \\
\text { estatísticas }\end{array}$ & $\begin{array}{c}\text { Relatórios } \\
\text { policiais/ } \\
\text { tribunais }\end{array}$ & $\begin{array}{c}\text { Menção ao } \\
\text { tráfico de } \\
\text { pessoas }\end{array}$ \\
\hline Angola & N/A & N/A & N/A & N/A & N/A & N/A & N/A \\
\hline Egito & Sim & Não & Não & Não & Sim & Não & Não \\
\hline Brasil & Sim & Sim & Sim & Sim & Sim & Sim & Sim \\
\hline Canadá & N/A & N/A & N/A & N/A & $\mathrm{N} / \mathrm{A}$ & N/A & N/A \\
\hline França & Sim & Não & Não & Não & Sim & Não & Não \\
\hline Turquia & Sim & Sim & Sim & Não & Não & Não & Sim \\
\hline Israel & N/A & N/A & N/A & N/A & N/A & N/A & N/A \\
\hline Índia & Sim & Sim & Sim & Sim & Sim & Sim & Sim \\
\hline Austrália & Sim & Não & Não & Não & Não & Sim & Sim \\
\hline Indonésia & Sim & Sim & Sim & Sim & Sim & $\operatorname{sim}$ & Sim \\
\hline
\end{tabular}

Fonte: Quadro elaborado pelos autores com base nos relatórios governamentais.

Legenda: N/A: Não se aplica

Esta etapa da análise é desenvolvida tendo as categorias informacionais como elementos condutores. O objetivo é o de facilitar o entendimento a respeito do fluxo de informações para o controle da aplicação das convenções estudadas.

Como ilustrado pelo quadro 3, no tocante ao conteúdo das informações enviadas no âmbito do controle da aplicação da Convenção no 29 , vigora a seguinte dinâmica informacional:

v Mudança na legislação: ${ }^{8}$ Todos os países que enviaram algum relatório desde o ano de 1990 ofereceram informação relativa a alguma mudança importante nas legislações nacionais para adequação aos dispositivos contidos na Convenção no 29. Variadas são as situações em que a legislação é adequada ao dispositivo internacional, seja com o foco na prevenção do fenômeno ou nas sanções impostas aos acusados da prática.

จ Políticas públicas ou programas de ação: ${ }^{9}$ Quatro dos sete países que proveram informações sobre a implementação da Convenção no 29 enviaram alguma informação relativa a programas ou políticas públicas adotadas pelos Estados com o objetivo de prevenir a prática do trabalho forçado em seus territórios. São estes países: Brasil, Turquia, Índia e Indonésia. O Brasil se destaca em relação aos outros países analisados quando observada a abrangência

\footnotetext{
${ }^{8}$ Modificações ocorridas nas legislações nacionais com o objetivo de se adequarem à Convenção no 29.

${ }^{9}$ Programas ou políticas governamentais desenvolvidas pelos Estados para enfrentar as práticas vedadas pela Convenção no 29 .
} 
informacional. Exemplo disso é o fornecimento detalhado de informações quanto ao Programa para a Erradicação do Trabalho Forçado e do Aliciamento de Trabalhadores (Perfor).

Resultado de programas ou ações públicas: ${ }^{10}$ Mais uma vez, apenas quatro países enviaram informações relevantes quanto à análise dos resultados obtidos por ações públicas empreendidas pelos Estados estudados. O caso indiano merece destaque por prover uma vastidão considerável de informações, especialmente a respeito de resultados alcançados a partir da implementação de políticas públicas, notadamente sobre os resultados positivos gerados a partir de campanhas publicitárias governamentais que visavam sensibilizar a população em face da situação da discriminação originada pelo sistema de organização social das castas. Esse sistema comumente é usado como argumento para a manutenção de situações de trabalho forçado em determinadas regiões da Índia.

、 Situações específicas: ${ }^{11}$ Três países proveram informações relevantes: Brasil, Índia e Indonésia. Embora não ofereçam maiores detalhes sobre as violações mencionadas, os relatórios dos países supracitados apresentam, em alguma medida, dados acerca de casos isolados em que o Estado falhou na missão de proteger seu cidadão em relação à exploração laboral. Exemplos disso são: o relatório de 2004 da Indonésia, que oferece informações sobre o caso de um grupo de crianças que estavam submetidas à situação de trabalho forçado em plataformas pesqueiras na costa nordeste do estado de Sumatra, e o relatório de 1998 do Brasil, que se posiciona diante das denúncias de trabalho forçado na destilaria Medasa, localizada no município de Medeiros Neto, estado da Bahia.

v Informações estatísticas: ${ }^{12}$ Observa-se que Egito, Brasil, França, Índia e Indonésia forneceram algum tipo de informação estatística para apreciação pelo comitê de peritos da OIT no âmbito da Convenção no 29. As estatísticas fornecidas apresentam baixíssima qualidade do ponto de vista da abrangência geográfica, setor da economia onde ocorre a violação e sobre as principais características das vítimas de trabalho forçado. Entretanto, o caso indonésio se configura como exceção ao anteriormente exposto, na medida em que oferece informações estatísticas precisas sobre a aplicação da Convenção no 29 especificamente no tocante às vítimas de tráfico humano.

v Relatórios policiais ou de tribunais: ${ }^{13}$ Quatro países (Brasil, Índia, Austrália e Indonésia) forneceram informações pertinentes. Deve-se destacar que essas informações se atêm principalmente ao número de casos de trabalho forçado denunciados em um determinado período de tempo e também às informações relacionadas aos julgamentos dos acusados de

\footnotetext{
${ }^{10}$ Informações qualitativas ou quantitativas sobre resultados de ações públicas com o foco no enfrentamento ao tráfico de pessoas.

${ }^{11}$ Informações sobre casos concretos e específicos de violações à Convenção no 29.

${ }^{12}$ Dados estatísticos absolutos ou relativos — em porcentagem — acerca dos temas abordados pela Convenção no 29.

${ }^{13}$ Informações oferecidas pelos Estados colhidas ou selecionadas a partir de relatórios policiais, tribunais ou de cortes de justiça nacionais.
} 
violação às garantias expressas no escopo da Convenção no 29 . Novamente, o caso brasileiro é destacado devido à vastidão de informações oferecidas sobre essa matéria.

v Menção ao tráfico de pessoas: ${ }^{14}$ Com relação ao tráfico de pessoas, observa-se que apenas dois países deixaram de enviar informações, sendo eles França e Egito. Entretanto, algumas considerações são necessárias. Dentre elas, o fato de Brasil e Indonésia informarem sobre a situação do tráfico de seres humanos, sem, contudo, utilizarem essa expressão em seus relatórios. O relatório brasileiro de 2002, por exemplo, informa sobre a situação de transferência ilegal de trabalhadores para outras partes do país e sobre o aliciamento de pessoas para o trabalho em plantações geograficamente afastadas para onde são levadas e lá permanecem sob a guarda dos aliciadores — situações em que comumente ocorre o tráfico de pessoas. Estes trabalhadores são forçados a laborar sob um regime que os reduz à situação análoga à de escravo e, dessa maneira, são impedidos de encerrar o contrato de trabalho. Já o relatório indonésio informa também sobre o aliciamento de trabalhadores, que são levados para campos de cultivo em ilhas afastadas. Em ambos os casos, a prática do tráfico de pessoas é percebida em sua modalidade intrafronteiriça. Contudo, os Estados acima citados parecem abordar a questão de maneira insegura e sem destreza conceitual. Diferentemente, os três últimos relatórios turcos — 2008, 2010 e 2011 — se dedicam quase que exclusivamente à problemática do tráfico de seres humanos, especialmente ao tráfico de mulheres e crianças com fins de exploração sexual. O país oferece informações detalhadas, inclusive estatísticas, sobre as diversas perspectivas do fenômeno do tráfico humano, o que revela um engajamento potencial do Estado em relação ao enfrentamento dessa problemática.

$$
\text { Quadro } 4
$$

\section{Tipologia das informações enviadas para monitoramento da implementação da Convenção no 105}

\begin{tabular}{|c|c|c|c|c|c|c|c|}
\hline País & $\begin{array}{c}\text { Mudança } \\
\text { na } \\
\text { legislação }\end{array}$ & $\begin{array}{l}\text { Políticas } \\
\text { públicas/ } \\
\text { programas }\end{array}$ & $\begin{array}{c}\text { Resultados } \\
\text { de ações } \\
\text { públicas }\end{array}$ & $\begin{array}{l}\text { Situações } \\
\text { específicas }\end{array}$ & $\begin{array}{l}\text { Informações } \\
\text { estatísticas }\end{array}$ & $\begin{array}{l}\text { Relatórios } \\
\text { policiais/ } \\
\text { tribunais }\end{array}$ & $\begin{array}{c}\text { Menção ao } \\
\text { tráfico de } \\
\text { pessoas }\end{array}$ \\
\hline Angola & Sim & Não & Não & Não & Não & Não & Não \\
\hline Egito & $\mathrm{Sim}$ & Não & Não & Não & Não & Não & Não \\
\hline Brasil & Sim & Sim & Sim & Sim & Sim & Sim & Sim \\
\hline Canadá & N/A & Não & Não & Não & Não & Não & Não \\
\hline França & Não & Não & Não & Não & Não & Não & Não \\
\hline Turquia & Sim & Não & Não & Não & Nào & Não & Não \\
\hline Israel & $N / A$ & N/A & $N / A$ & $\mathrm{~N} / \mathrm{A}$ & N/A & N/A & $\mathrm{N} / \mathrm{A}$ \\
\hline Índia & N/A & N/A & N/A & $\mathrm{N} / \mathrm{A}$ & N/A & N/A & N/A \\
\hline Austrália & $\mathrm{N} / \mathrm{A}$ & $\mathrm{N} / \mathrm{A}$ & N/A & N/A & N/A & N/A & N/A \\
\hline Indonésia & Não & Não & Não & Não & Não & Não & Não \\
\hline
\end{tabular}

Fonte: Quadro elaborado pelos autores com base nos relatórios governamentais.

Legenda: N/A: Não se aplica

${ }^{14}$ Informações relacionadas exclusivamente ao tráfico no âmbito do Estado signatário da Convenção no 29. 
Assim como elaborado anteriormente, a análise do fluxo de informações produzido em função do monitoramento da Convenção no 105 sobre a eliminação do trabalho forçado é desenvolvida a partir das categorias informacionais selecionadas. ${ }^{15} \mathrm{O}$ quadro 4 apresenta a dinâmica informacional no escopo da referida Convenção.

จ Mudança na legislação: França e Indonésia são os únicos países que não enviaram informações sobre as mudanças legislativas empreendidas em função das disposições contidas na Convenção no 105 . Dos 10 países analisados, três não enviaram nenhum relatório sobre a aplicação dessa Convenção. Destacam-se o caso angolano, em que uma lei que previa prisão e trabalho forçado para trabalhadores que comprometessem a produção, quer por greve ou por paralisia passiva, foi revogada em 1992; e o caso turco, que oferece muitas informações sobre o debate existente no âmbito legislativo nacional para uma maior conformidade com a Convenção no 105 .

- Políticas públicas ou programas de ação: Observa-se que apenas o Brasil proveu informações relevantes. As informações oferecidas pelo Estado brasileiro apresentam notável abrangência e descrição detalhada dos programas, dentre os quais figura o Programa para a Erradicação do Trabalho Infantil (Peti). Desse modo, cabe dizer que, em função dessa situação, somente o Brasil apresentou informações em seus relatórios sobre resultados alcançados pelos programas e políticas públicos desenvolvidos.

v Demais categorias: Após perita análise de todos os relatórios enviados a partir de 1990 ao comitê que avalia a aplicação das normas internacionais da Convenção no 105, observa-se que somente o Brasil enviou informações acerca de violações relacionadas a essa prática, incluindo estatísticas e informações oriundas de relatórios policiais. Já no que diz respeito às menções ao tráfico de pessoas, o Brasil se comportou de forma idêntica ao apresentado quanto à Convenção no 29 , ou seja, informou sobre o fenômeno do aliciamento de pessoas que são deslocadas de seus locais de origem por meio de promessas enganosas e que acabam por se endividar grandemente e, dessa forma, são forçadas a trabalhar para saldar tal dívida - algo que muitas vezes não chega a acontecer. Percebe-se novamente que a expressão "tráfico de pessoas" não é empregada para qualificar a prática acima relatada.

\section{Considerações finais}

A análise das informações ora apresentadas revela que os países, de um modo geral, assumem uma postura indesejável no que tange ao envio das informações acerca do cumprimento das Convenções no 29 e nº 105 e, via de consequência, do tráfico de pessoas.

\footnotetext{
${ }^{15}$ As categorias informacionais apresentam as mesmas definições da análise desenvolvida em função do quadro 3.
} 
Cabe destacar, mais uma vez, que muito embora o tráfico de seres humanos merecesse tratamento apartado, ele é analisado de forma incidental ao trabalho forçado, em virtude da ausência de uma Convenção de cunho trabalhista específica sobre o tema. Não custa ainda relembrar que o tráfico humano e o trabalho forçado podem se tangenciar, mas essa não é uma condição necessária. Assim, determinado trabalhador pode ser submetido a trabalho forçado em virtude de ter sido traficado ou se encontrar em tal condição de trabalho forçado sem que tenha sido também vitimado pela ação de um traficante de pessoas.

Nesse sentido, a pesquisa empreendida serviu para confirmar os grandes obstáculos gerados pela ausência de tratamento trabalhista da questão do tráfico de pessoas e pela inexatidão conceitual que prepondera entre os países, que adotam, muitas vezes, definições distintas e, até mesmo, incompatíveis de tráfico humano. Esse problema, entretanto, não se deve tão somente ao fato de alguns países não terem ratificado o Protocolo de Palermo, pois, ainda que adotem a sua definição, encontram nela espaço para promover interpretações vastas. ${ }^{16}$

Assim, a observação dos dados revelou que há reiterado descumprimento do dever de informar e evidente negligência quanto aos prazos e periodicidade solicitados. Ademais, as informações enviadas padecem de despadronização decorrente, ao que tudo indica, da própria imprecisão da definição trazida pelo Protocolo de Palermo, demasiadamente ampla em alguns aspectos, e da heterogeneidade do tratamento interno da matéria em cada país. Um aspecto que vem corroborar o exposto é o fato de apenas a Turquia utilizar expressamente o termo "tráfico de pessoas" e, mesmo assim, restringindo-o à sua manifestação no caso da exploração sexual.

No que tange especificamente à Convenção no 105, é de se destacar a sua patente fragilidade em seu potencial informacional, dado que apenas o Brasil ofereceu informações sobre as outras categorias informacionais que não sobre mudanças na legislação.

Curiosamente, a investigação empreendida nesse trabalho ainda contribui para a desconstrução do mito da absoluta superioridade dos países mais desenvolvidos. Nesse sentido, constatou-se que, à exceção de Israel — que não enviou nenhum relatório —, a França e o Canadá apresentaram os piores desempenhos informacionais. Em oposição, o Brasil e a Turquia apresentaram os melhores desempenhos.

Por todo o exposto, foi possível concluir que a problemática derivada da imprecisão conceitual, que pode parecer, em um primeiro momento, de pouca relevância, acarreta inúmeros problemas no que tange à coleta e divulgação de informações fidedignas a respeito do tráfico de pessoas. Além disso, o referido impasse implica uma abordagem incompleta do

\footnotetext{
${ }^{16}$ Dentre o rol de países analisados, apenas Angola não ratificou o Protocolo de Palermo. A lista completa de países que o ratificaram pode ser conferida em: <http://treaties.un.org/Pages/ViewDetails.aspx?src=TREATY\&mtdsg no $=$ XVIII-12-a\&chapter $=18 \&$ lang $=\mathrm{en}>$.
} 
fenômeno, pois, focando-se exclusivamente no aspecto penal, nega-se às vítimas tratamento compatível com as noções de trabalho decente e de tutela dos direitos humanos.

\section{Referências}

ANDERSON, Bridget; O'CONNELL DAVIDSON, Julia. Is trafficking in human beings demand driven? A multi-country pilot study. Genebra: OIM, 2003. 54 p. Disponível em: <www.compas.ox.ac.uk/ fileadmin/files/Publications/Reports/Anderson04.pdf>. Acesso em: 1o mar. 2013.

ANDREES, Beat; N. J. VAN DER LINDEN, Mariska. Designing Trafficking research from a labour market perspective: the ILO experience. In: LACZKO, Frank; GOZDZIAK, Elzbieta (Ed.). Data and research on human trafficking: a global survey. Geneva: OIM, 2005. p. 55-74.

BARZOTTO, Luciane C. Direitos humanos e trabalhadores: atividade normativa da Organização Internacional do Trabalho e os limites do direito internacional do trabalho. Porto Alegre: Livraria do Advogado, 2007.

BLOTTA, Vitor S. L.; MATTOS, Fernando A. M. Mídia, política e controle social da informação. América Del Sur, Buenos Aires, v. 2, n. 1, p. 1-28, 2008.

ESCRITÓRIO DAS NAÇÕES UNIDAS SOBRE DROGAS E CRIMES (UNODC). Global report on trafficking in persons. Disponível em: <www.unodc.org/southerncone/pt/trafico-de-pessoas/publicacoes. html>. Acesso em: 30 set. 2011.

GAATW. Collateral damage: the impact of anti-trafficking measures on human rights around the world. Bangkok: Printed at Amarin Printing \& Publishing Public Company Limited, 2007. Disponível em: <www.gaatw.org/Collateral\%20Damage_Final/singlefile_CollateralDamagefinal.pdf > . Acesso em: 22 fev. 2013.

GAUDEMAR, Jean-Paul de. Mobilidade do trabalho e acumulação do capital. Lisboa: Estampa, 1997.

GRUPO DAVIDA. Prostitutas, "traficadas" e pânicos morais: uma análise da produção de fatos em pesquisas sobre o "tráfico de seres humanos". Cadernos Pagu, n. 25, p. 153-184, jul./dez. 2005.

GUERALDI, Michelle; DIAS, Joelson. Em busca do éden: tráfico de pessoas e direitos humanos, experiência brasileira. São Paulo: Max Limonad, 2012.

HILTON, Margaret. Monitoring international labor standards: quality of information. Washington: The National Academies Press, 2003.

IBGE. Instituto Brasileiro de Geografia e Estatística. Departamento Intersindical de Estatística e Estudos. Aspectos conceituais da vulnerabilidade social. Brasília: Convênio MTE-Dieese, 2007. 31 p. Disponível em: <www.mte.gov.br/observatorio/sumario_2009_TEXTOV1.pdf>. Acesso em: 12 fev. 2012. 
ILO. International Labor Organization. ILO Declaration on fundamental principles and rights at work. Disponível em: <www.ilo.org/public/english/standards/relm/ilc/ilc86/com-dtxt.htm>. Acesso em: 30 mar. 2011.

ILO. International Labor Organization. International Labor Organization constitution. Disponível em: <www.ilo.org/ilolex/english/constq.htm>. Acesso em: 30 mar. 2012.

ILO. International Labor Organization. International labour migration: a rights-based approach. Geneva: ILO, 2010. Disponível em: <www.ilo.org/wcmsp5/groups/public/---dgreports/---dcomm/ documents/publication/wcms_125362.pdf>. Acesso em: 20 mar. 2013.

INTERNATIONAL ORGANIZATION FOR MIGRATION. World migration report: communicating effectively about migration. Geneva, 2011.

JESUS, Damásio de. Tráfico internacional de mulheres e crianças: Brasil: aspectos regionais e nacionais. São Paulo: Saraiva, 2003.

KAPUR, Ratna. Cross-border movements and the law: renegotiating the boundaries of difference. In: KEMPADOO, Kamala; SANGUERA, Jyoti; PATTANAIK, Bandana. Trafficking and prostitution reconsidered: new perspectives on migration, sex work, and human rights. $2^{\text {nd }}$ ed. Londres: Paradigm Publishers, 2012. p. 25-42.

KEMPADOO, Kamala. Mudando o debate sobre o tráfico de mulheres. Cadernos Pagu, n. 25, p. 55-78, jul./dez. 2005.

KEMPADOO, Kamala; SANGUERA, Jyoti; PATTANAIK, Bandana. Trafficking and prostitution reconsidered: new perspectives on migration, sex work, and human rights. $2^{\text {nd }}$ ed. Londres: Paradigm Publishers. 2012.

LACZKO, Frank; GOZDZIAK, Elzbieta (Ed.). Data and research on human trafficking: a global survey. Geneva: OIM, 2005.

MARX, Karl. O capital: crítica da economia política. São Paulo: Abril Cultural, 1993. v. I, c. I.

MÉSZÁROS, István. Desemprego e precarização: um grande desafio para a esquerda. 2003. Disponível em: <http://resistir.info/crise/desemprego_precarizacao.html>. Acesso em: 14 mar. 2013.

MORGAN, Stephen L.; GRUSKY, David B.; FIELDS, Gary S. (Ed.). Mobility and inequality: frontiers of research in sociology and economics. Stanford, California: Stanford University Press, 2006.

NATIONAL RESEARCH COUNCIL. Monitoring international labor standards: techniques and sources of information. Washington, DC: The National Academies Press, 2004.

NOVAIS, Denise P. V. Tráfico de pessoas para fins de exploração do trabalho: um estudo sobre o tráfico de bolivianos para exploração do trabalho em condição análoga à de escravo na cidade de São Paulo. Tese (doutorado) — Faculdade de Direito, Universidade de São Paulo, São Paulo. 2008.

OIT. Organização Internacional do Trabalho. Convenção nº 29 da Organização Internacional do Trabalho sobre o trabalho forçado ou obrigatório. 1930. 
OIT. Organização Internacional do Trabalho. Convenção no 105 da Organização Internacional do Trabalho sobre a abolição do trabalho forçado. 1957.

OIT. Organização Internacional do Trabalho. Declaração sobre os princípios e direitos fundamentais no trabalho. 1998. Disponível em: <www.oitbrasil.org.br/inst/fund/docs/index.php>. Acesso em: 20 mar. de 2011.

OIT. Organização Internacional do Trabalho. Não ao trabalho forçado: relatório global do seguimento da declaração da OIT relativa a princípios e direitos fundamentais no trabalho. Brasília: OIT, 2001.

OIT. Organização Internacional do Trabalho. O custo da coerção: relatório global no seguimento da declaração da OIT sobre os direitos fundamentais do trabalho. Brasília: OIT, 2009.

OIT. Organização Internacional do Trabalho. O que é trabalho decente. Disponível em: <www.oit. org.br/content/o-que-e-trabalho-decente>. Acesso em: 5 mar. 2012.

OIT. Organização Internacional do Trabalho. Perfil dos principais atores envolvidos no trabalho escravo rural no Brasil. Brasília: OIT, 2011. v. 1.

OIT. Organização Internacional do Trabalho. Uma aliança global contra o trabalho forçado: relatório global do seguimento da declaração da OIT sobre princípios e direitos fundamentais no trabalho. Brasília: OIT, 2005.

PISCITELLI, Adriana. Entre as "máfias" e a "ajuda": a construção de conhecimento sobre tráfico de pessoas. Cadernos Pagu, n. 31, p. 29-63, jul./dez. 2008.

REIS, Daniela Muradas; REIS, Priscila Martins. A vulnerabilidade como condição comum às vítimas do tráfico de seres humanos para a exploração do trabalho. In: CONGRESSO NACIONAL DO CONPEDI, XX, 2011, Vitória, ES. Anais... Florianópolis: Fundação Boiteux. 2011. v. 1, p. 5399-5428.

SANGUERA, Jyoti. Unpacking the trafficking discourse. In: KEMPADOO, Kemala; SANGUERA, Jyoti; PATTANAIK, Bandana. Trafficking and prostitution reconsidered: new perspectives on migration, sex work, and human rights. $2^{\text {nd }}$ ed. Londres: Paradigm Publishers, 2012. p. 3-24.

SPRANDEL, Márcia Anita; PENNA, Rodrigo P. M. ORGANIZAÇÃO INTERNACIONAL DO TRABALHO. Cooperação e coordenação policial no Mercosul e Chile para o enfrentamento ao tráfico de pessoas. Brasília: OIT, 2009.

STALKER, Peter. The work of strangers: a survey of international labour migration. Geneva: International Labour Office, 1994.

UNITED NATIONS DEPARTMENT OF ECONOMIC AND SOCIAL AFFAIRS. United Nations. Forthcoming international migration flows to and from selected countries: the 2010 revision. Nova York, 2010.

UNITED NATIONS. Protocol to prevent, supress and punish trafficking in persons especially women and children, supplementing the United Nations Convention against transnational organized crime. 2000. Disponível em: <www2.ohchr.org/english/law/protocoltraffic.htm>. Acesso em: 15 fev. 2012. 
WEEKS, Gregory B.; WEEKS, John R. Irrestible forces: Latin America migration to the United States and its effects on the South. Albuquerque, NM: University of New Mexico Press, 2010.

WORLD BANK. Migration and remittances factbook 2011. $2^{\text {nd }}$ ed. Washington: World Bank, 2011.

Priscila Martins Reis é advogada, mestranda em direito pelo Programa de Pós-Graduação da Faculdade de Direito da Universidade Federal de Minas Gerais (UFMG). E-mail: mreispriscila@hotmail.com.

Pedro Alves Barbosa Neto é doutorando em ciência da informação pela Universidade Federal de Minas Gerais (UFMG), pesquisador vinculado à Université du Québec à Montréal (UQAM). E-mail: pedrocorone@hotmail.com. 